\title{
A New Diterpene Extracted from Daphne Mucronata, Effects on Human K562 and CCRF-CEM Cell Lines
}

\author{
Mehdi Hedayati ${ }^{1}$, Razieh Yazdanparast ${ }^{2}$, Marjan Zarif Yeganeh ${ }^{1}$, Laleh Hoghooghi Rad ${ }^{1}$, \\ Fereidoun Azizi ${ }^{3}$
} ${ }^{1}$ Obesity Research Center, Research Institute for Endocrine Sciences, Shahid Beheshti University of Medical Sciences, Tehran, Iran;
${ }^{2}$ Institute of Biochemistry and Biophysics, Tehran University, Tehran, Iran; ${ }^{3}$ Endocrine Research Center, Research Institute for En-
docrine Sciences, Shahid Beheshti University of Medical Sciences, Tehran, Iran.
Email: hedayati@endocrine.ac.ir

Received October $9^{\text {th }}, 2010$; revised November $12^{\text {th }}, 2010$; accepted November $17^{\text {th }}, 2010$.

\begin{abstract}
Background: Daphne Mucronata extract has a decreasing effect on the size of breast adenocarcinoma in rats. So in this study, the effect of Daphne Mucronata purified diterpene were investigated on co culture of human monocytes and two human leukemia cell lines (K562, CCRF-CEM). Materials and Methods: Each cell line mono-layer culture, in log phase growth, was treated with 10 to $160 \mu \mathrm{L}$ of the extract $(1 \mathrm{~g} / \mathrm{ml}$ leave powder) and purified compound $(0.94 \mathrm{nM})$. For a comparative study, Taxol (5 to $40 \mu M)$ was used in the presence and absence of LPS. Human monocytes were isolated by adhesion method. TNF- $\alpha$ in cultured media were measured by sensitive biotin-streptoavidin ELISA method. Results: Fifty percent of growth inhibition was shown by $160 \mu \mathrm{L}$ (1:100 dilution, $0.5 \mathrm{~g}$ of the powdered leaves $/ \mathrm{ml})$ of the extract and $0.94 \mathrm{nM}$ of the purified component, and there was more inhibition in K562 cells $(P<0.05)$. Four fold increases in growth inhibition was shown in co culture of isolated human monocytes and leukemia cell lines. There was a direct relationship between monocytes TNF- $\alpha$ secretion and growth inhibition degree. Conclusion: Daphne Mucronata extract and its purified diterpene through increasing monocytes $T N F-\alpha$ releasing, potentially inhibit Leukemia cell line.
\end{abstract}

Keywords: TNF- $\alpha$, Leukemia, Daphne Mucronata, K562, CCRF-CEM

\section{Introduction}

Various Daphne species (Tymelaeaceae) have been used to treat cancer since $200 \mathrm{AD}[1-4]$. There are so many reports on effects of Tymelaeaceae family in different parts of body, for example their; anti leukemia [5], emergency abortion [6], anti tumor [7], anti gout [8], anti microbial [9] and anti inflammatory [10] effects of Tymelaeaceae family $[11,12]$. We reported inhibition of nucleic acid synthesis [13], inhibition of cell adhesion [14], and anti rat breast adenocarcinoma effect [15] of Daphne mucronata and Dendrostellera lessertii [16] in Iranian folk medicine. Therefore, as part of our studies on plants for new anticancer agents with emphasis on Tymelaeaceae family, we examined the cytotoxicity and anti-tumor activity of an alcohol: water $(1: 1, \mathrm{v} / \mathrm{v})$ extract of Daphne mucronata leaves and one of its purified diterpene (Gnidilatimonoein) against two types of human leukemia cell lines. After exploring the high anti-tumor activity of plant extract, and its purified compound on human leukemia cell lines, we evaluated the mode of action of this anti-cancer plant. In that respect, we investigated the effects of the plant extract, and the purified component, and Taxol (an antineoplastic natural agent from the bark of the Pacific yew tree and with established mechanism of action) on the TNF- $\alpha$ secretion by the isolated human monocytes in the absence or the presence of LPS. Based on the literature data, Taxol inhibits cell growth by two mechanisms of cell cycle dependent and independent pathways. In cell cycle independent pathway, it rapidly down-regulates TNF- $\alpha$ receptors and stimulates TNF- $\alpha$ release by the isolated human monocytes in a similar way to LPS [17-20]. Leukemia treatment is an important medical problem. So in this study we investigated the Daphne mucronata extract and its purified diterpene (Gnidilatimonoein) effects on the isolated healthy human monocytes and the co-culture of 
human monocytes and two, chronic and acute, leukemia cell lines in the presence and absence of LPS as monocytes stimulant.

\section{Materials \& Methods}

Human tumor necrosis factor alpha (TNF- $\alpha)$, Salmonella typhimurium LPS, RPMI 1640, Neomycin, Penicillin and other chemicals was purchased from Sigma Chemical Co. (Sigma-Aldrich Chime GmbH, Germany). Radioactive $\mathrm{NaI}^{125}$ was obtained from Atomic Energy Agency of Iran. Human leukopakes of normal donors were obtained from Blood Transfer Institute of Iran. Human leukemia cell lines, K562 (Chronic Mylocytic Leukemia), CCRF-CEM (Acute Lymphocytic Leukemia) were obtained from Iranian Cell Bank.

\subsection{Plant Material}

Aerial parts of Daphne mucronata (Magnoliopsida, Malvales, Thymelaeaceae, Daphne, mucronata) were collected from suburb of Kermanshah province at the end of spring. A voucher specimen was deposited in the herbarium of the faculty of Science, Tehran University (7658 THE). The plant material was dried, in the absence of direct light. The dried leaves were separated from the stems and powdered. The powder was kept in a closed container in a cold room.

\subsection{Extraction}

Extract solution was made with $500 \mathrm{~g}$ of powder in 7.5 liter of the solvent mixture and finally was concentrated to $500 \mathrm{~mL}$. Briefly, each 100 gram of the powder extracted with $3 \times 500 \mathrm{~mL}$ of EtOH-H2O (50:50, v/v), placed under agitation during $24 \mathrm{~h}$. After filtration, the extracts are concentrated with a rotary evaporator, under reduced pressure, finally kept at freezer $\left(-20^{\circ} \mathrm{C}\right)$ for further investigation [21-23].

\subsection{Purification}

On the basis of Yazdanparast and her coworkers' method, its active diterpene (Gnidilatimonoein) extracted and purified [24].

\subsection{LC50 Estimation}

The biological potency of plant extract was established through using brine shrimp (Artemia Solina) test as described by Mclaughlin and coworker [25]. Different amount of extract were transferred to sample vials containing 10 shrimps, $5 \mathrm{~mL}$ with sea water and a drop of dry yeast suspension $(3 \mathrm{mg} / \mathrm{mL})$. The vials were kept under the light and in the room temperature. After 24 hours the survivors were counted and their death percentage were determined at each dose. In the case of death in the controlled vials, the data were corrected by using the following formula: \% death $=[($ test - control $)] /$ control 100

The LC50 were determined for each dose by using the probity analysis method which described by Finney [26].

\subsection{Monocytes Isolation}

Human monocytes were isolated from leukopakes by Cell adherence separation method. Briefly, cells were washed twice with Phosphate Buffer Saline (PBS), counted and suspended in the culture media at a final concentration of $5 \times 10^{6}$ cells $/ \mathrm{mL}$. After two hours of incubation at $37^{\circ} \mathrm{C}$ in an incubator with $5 \% \mathrm{CO}_{2}$ atmosphere, the non adherent cells were removed aseptically followed by 3-4 times of washing with cold PBS. The adherent cells were gently scraped with a rubber policeman in the presence of PBS/EDTA solution. The cells were finally re-suspended in the culture media at a concentration of $5 \times 10^{5}$ cells $/ \mathrm{mL}$ [27].

\subsection{Cell Cultures and Treatments with Stimuli}

A total of $10^{6}$ cells were incubated in duplicate, in 24well plate. Each well contained the medium (RPMI 1640 containing 10\% BCF, $100 \mathrm{IU}$ penicillin, plus $100 \mu \mathrm{g} / \mathrm{mL}$ of streptomycin). After 20 hours incubation the cells in incubator at $37^{\circ} \mathrm{C}$ in a $5 \% \mathrm{CO}_{2}$ atmosphere, various concentrations of Daphne mucronata extract and its purified diterpene were added to each well up to a final volume of $1 \mathrm{~mL}$. The cultures were incubated with the extract and purified diterpene for 24 hours at $37^{\circ} \mathrm{C}$ in a $5 \% \mathrm{CO}_{2}$ atmosphere. The stimuli (crude extract and purified diterpene) were: plant extract $(0 \mathrm{mg} / \mathrm{ml}, 10 \mathrm{mg} / \mathrm{ml}, 20 \mathrm{mg} / \mathrm{ml}$, $40 \mathrm{mg} / \mathrm{ml}, 80 \mathrm{mg} / \mathrm{ml}$, and $160 \mathrm{mg} / \mathrm{ml}$ of a $1: 100$ dilution of the original plant extract with a concentration corresponding to $1 \mathrm{~g}$ plant leaves powder per $\mathrm{mL}$ ), and its purified diterpene $(0.94 \mathrm{nM})$, in the presence and absence of LPS $(100 \mathrm{ng} / \mathrm{mL})$. The effect was compared with Taxol $(0,5 \mu \mathrm{M}, 10 \mu \mathrm{M}, 20 \mu \mathrm{M}$ and $40 \mu \mathrm{M})$ as a positive control.

\subsection{Determination of hTNF- $\alpha$}

The hTNF- $\alpha$ level in the supernatant of each culture monocytes sample was achieved by our developed biotin-streptavidin enzyme immunoassay system [28]. Each sample supernatant (or the diluted sample 1:10) was added to a well of a 96 well plate $(100 \mu \mathrm{L} /$ well $)$. The plate was incubated at room temperature for one hour on a plate shaker. After washing, $100 \mu \mathrm{L}$ of biotinylated antibody was added to each well, incubated at room temperature for one hour on a plate shaker and rinsed with the wash buffer (PBS with 0.05\% TWEEN 20). Then $100 \mu \mathrm{l}$ of streptavidin-HRP conjugate was added to each well followed by 30 minutes of incubation at room temperature while shaking on the plate shaker. Finally 
the plate was washed and the color was developed by adding the substrate buffer solution containing TMB and $\mathrm{H} 2 \mathrm{O} 2(100 \mu \mathrm{L} /$ well). The reaction was stopped after 30 minutes by the addition of $100 \mu \mathrm{l}$ of $1.8 \mathrm{M}$ sulfuric acid. The optical density of each well was recorded at $450 \mathrm{~nm}$ in an ELISA plate reader (Spectra, Tecan, Austria). The levels of the TNF- $\alpha$ in each sample were established via the use of the corresponding calibration graph.

\section{Results}

Based on experiments carried out on shrimp test, biological potency of Daphne mucronata extract LC50 was $0.062 \mathrm{mg} / \mathrm{ml}$ plant leave and $0.3 \mathrm{mg} \mathrm{mg} / \mathrm{ml}$ plant stem. The effects of Daphne mucronata extract and its purified diterpene (Gnidilatimonoein, MW 663) on acute and chronic leukemia cell lines are shown in Figure 1. These data clearly show that the purified component is biologically active. In the presence of the human monocytes, and under all identical conditions, cell viability decreased almost by a factor of four (Figure 2). In other words, the concentration of the plant extract or the purified component required a half reduction in cell number, decreased considerably and statistically significant for the crude extract and also for the purified component (Figure 2). Determination of TNF- $\alpha$ in the cell culture media of the co-culture revealed that under the effect of the plant extract and its purified active component (Figure 3) the concentration of TNF- $\alpha$ increase in a dose dependent way. It is interesting to note that the effects of the purified compound and LPS on TNF- $\alpha$ secretion by the monocytes are neither addition nor synergistic.

The results are presented as the mean $\pm \mathrm{SD}$ of three independent experiments in duplicate.

Comparison between two groups was done with t-test and between groups according ANOVA test, (the significance consider for $\mathrm{P} \leq 0.05$ ).

\section{Discussion}

Tymelaeaceae family has been used to treat diseases from many years ago [2]. Daphne is the most important genus in the Tymelaeaceae family. There are many reports about Daphne therapeutic effects [5-8]. Daphne mucronata is specific to Iranian folk medicine. At first we reported the effects of its alcohol: water inhibition on nucleic acid synthesis and cell adhesion [13,14]. Our investigations showed that Daphne Mucronata extract has a decreasing effect on the size of breast adenocarcinoma in rats and stimulate TNF- $\alpha$ releasing from monocytes [15]. Taxol is an antineoplastic natural agent which extracted from the bark of the Pacific yew tree and established as an effective drug for many types of cancers [16-18]. Based on the literature data, Taxol inhibits cell growth by cell cycle independent pathway through mo-

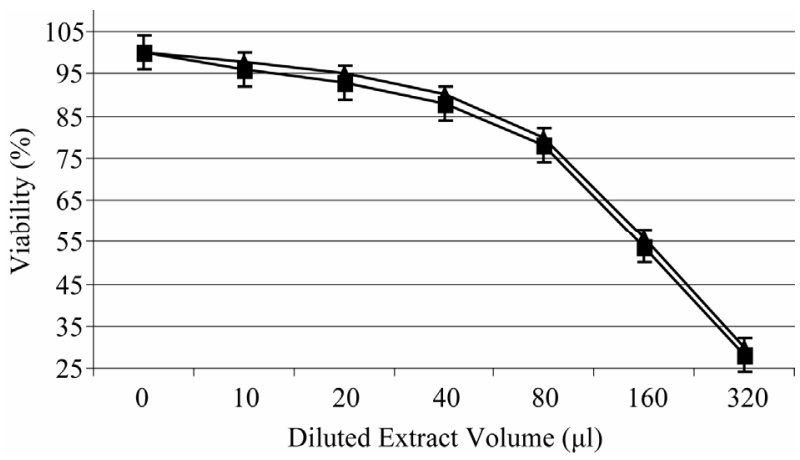

(a)

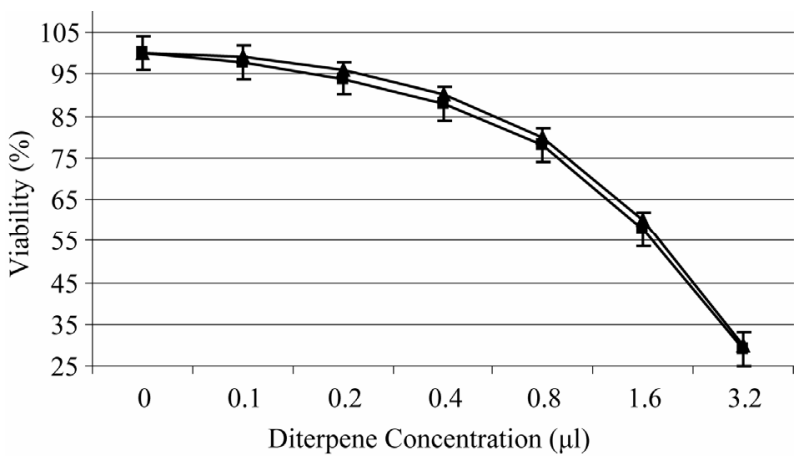

(b)

Figure 1. Daphne mucronata diluted (1:100) extract (a) and its diterpene (b) effect on leukemia cell viability, k562 (a), CCRF-CEM ( $\Delta)$.

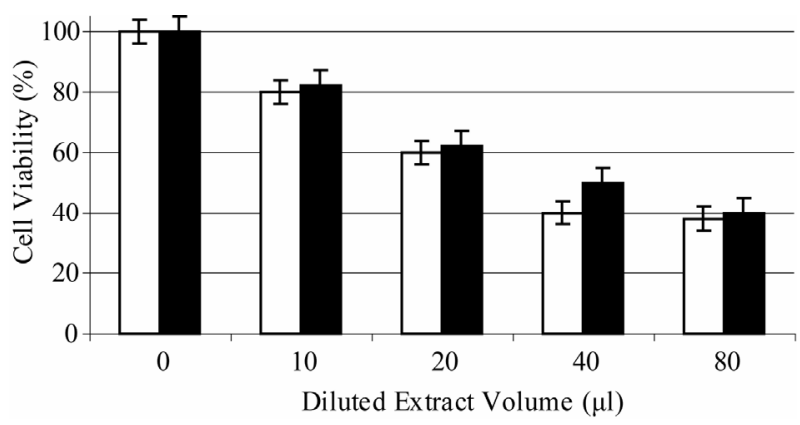

(a)

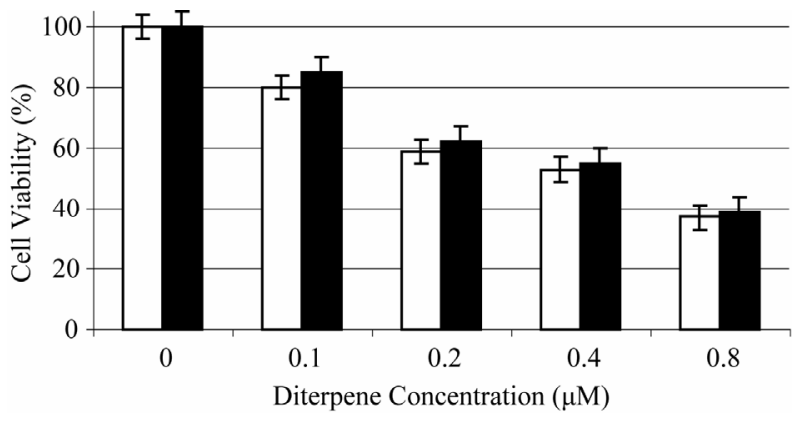

(b)

Figure 2. Daphne mucronata diluted (1:100) extract (a) and its diterpene (b) effect on leukemia cell viability, k562 (white), CCRF-CEM (black) in co culture with human monocytes. 


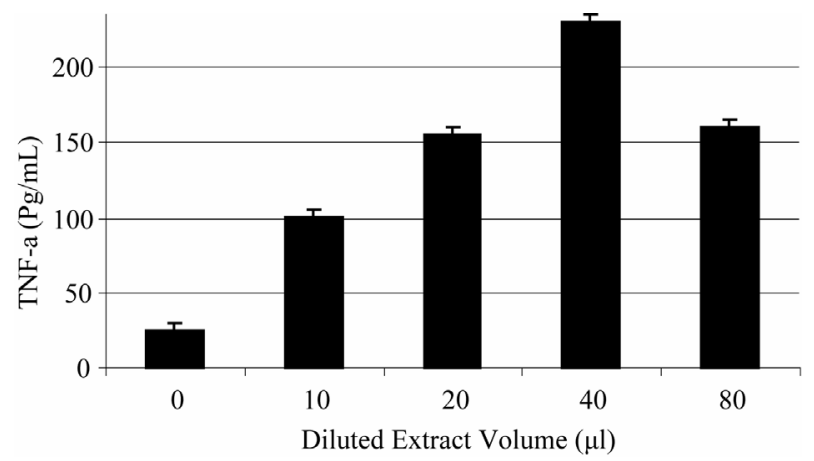

(a)

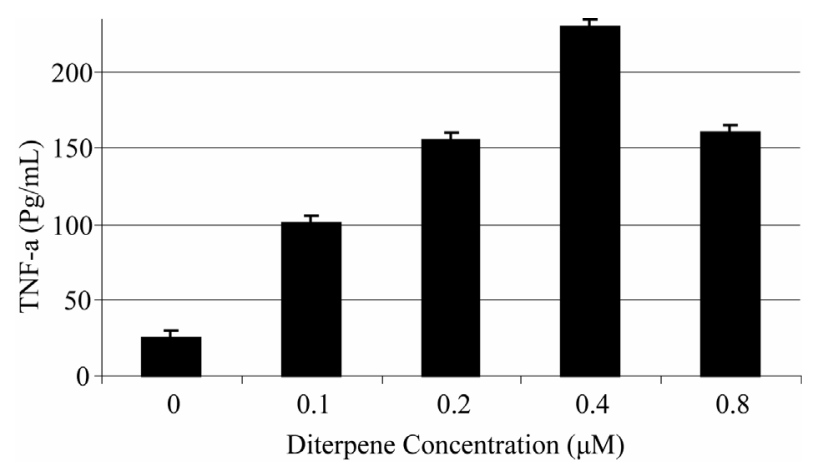

(b)

Figure 3. Daphne mucronata extract (a) and its diterpene (b) effect on TNF-a secretion in co culture of human monocytes and leukemia cell lines.

nocytes/macrophage TNF- $\alpha$ release stimulation [16,18]. On the basis of our reported data, alcohol: water extract of Daphne mucronata and its purified component showed similar effects on the isolated healthy human monocytes activation [15,29]. In this study after exploring the high anti-tumor activity of plant extract, and its purified diterpene (Gnidilatimonoein) on human leukemia cell lines, we evaluated the mode of action of this anticancer plant. In that respect, we investigated the effects of the plant extract, and the purified component, on TNF- $\alpha$ secretion by the isolated human monocytes in the absence or the presence of LPS. The co-culture of human monocytes and two, chronic and acute leukemia cell lines showed non additive and non synergistic properties between the plant extract and LPS. Based on these observations, it may be concluded that the higher sensitivity of K562 and CCRF-CEM cells to Daphne mucronata, in the co-culture samples, is most probably due to the secretion of TNF- $\alpha$ by the monocytes. We hope this diterpene, after evaluating its side effects; become an effective drug against human leukemia.

\section{Acknowledgment}

We are thankful to Endocrine Research Center of Shahid Beheshti University of Medical Sciences for providing the financial support of this investigation. The authors also wish to thank Prof. David L. Smith for providing the $\mathrm{FAB} / \mathrm{MS}$ of the purified active components of D. $m u$ cronata.

\section{REFERENCES}

[1] F. Abe, Y. Iwase, T. Yamauchi, K. Kinjok and S. Yaga, "Daphnane Diterpenoids from the Bark of Winstromia Etusa," Phytochemistry, Vol. 44, 1997, pp. 643-646. doi:10.1016/S0031-9422(96)00602-4

[2] K. Baba, K. Takeuchi, F. Hamaski and M. Kozawa, "Chemical Studies on the Constituents of the Thimelaeceous Plants," Thunb Chemical Pharmaceutical Bulletin, Vol. 34, 1986, pp. 595- 598.

[3] R. Kasai, K. Lee and H. Huang, "Antitumor Agent 40. Genkawaphnin a Potent Anti-Leukemic Diterpene from Daphne Genkawa," Phytochem, Vol. 20, 1981, pp. 25922595.

[4] S. M. Kupchan and R. L. Baxter, "Mezerin: Antileukemic Principle Isolated from Daphne Mezerum," Science, Vol. 187, 1975, pp. 652-654. doi:10.1126/science.1114315

[5] K. Larsen, "Medicinal and Poisonous Plants. IV. Daphne Mezereum," Nord Medical, Vol. 15, 1962, pp. 227-228.

[6] S. M. Kupchan and R. L. Baxter, "Mezerein: Antileukemic Principle Isolated from Daphne Mezereum L," Science, Vol. 187, 1975, pp. 652-653. doi:10.1126/science.1114315

[7] X. M. Zhang, C. M. Wang, Y. H. Cen, H. S. Huo, J. Y. $\mathrm{Ba}, \mathrm{Z}$. T. Liu, et al., "Clinical Observation and Preliminary Study of Termination of Early Pregnancy by Administration of Yellow Daphne," Shengzhi Yu Biyun, Vol. 4, 1984, pp. 42-46.

[8] T. Noro, Y. Oda, T. Miyase, A. Ueno and S. Fukushima, "Inhibitors of Xanthine Oxidase from the Flowers and Buds of Daphne Genkwa," Chemical Pharmaceutical Bulletin (Tokyo), Vol. 31, 1983, pp. 3984-3987.

[9] F. Cottiglia, G. Loy, D. Garau, C. Floris, M. Casu, R. Pompei, et al., "Antimicrobial Evaluation of Coumarins and Flavonoids from the Stems of Daphne Gnidium L," Phytomedicine, Vol. 8, 2001, pp. 302-305. doi:10.1078/0944-7113-00036

[10] E. Yesilada, H. Taninaka, Y. Takaishi, G. Honda, E. Sezik, H. Momota, et al., "In Vitro Inhibitory Effects of Daphne Oleoides ssp. Oleoides on Inflammatory Cytokines and Activity-Guided Isolation of Active Constituents," Cytokine, Vol. 13, No. 6, 2001, pp. 359-364. doi:10.1006/cyto.2001.0838

[11] D. Parish, "Daphne Parish: Nursing Freedom," Nursing, Vol. 4, No. 24, 1990, pp. 19-20.

[12] T. Nikaido, T. Ohmoto and U. Sankawa, "Inhibitors of Adenosine 3',5'-Cyclic Monophosphate PhosphodiEsterase in Daphne Genkwa Sieb," Chemical Pharmaceutical Bulletin (Tokyo), Vol. 35, No. 2, 1987, pp. 675681.

[13] M. Mianabadi and R. Yazdanparast, "Inhibition of Sub- 
strate-Tumor Cell Adhesion under the Effect of Gnidilatimonoein Purified from Daphne Mucronata," American Journal of Chinese Medicine, Vol. 32, No. 3, 2004, pp. 369-376. doi:10.1142/S0192415X04002028

[14] R. Yazdanparast and H. Sadeghi, "Nucleic Acid Synthesis in Cancerous Cells under the Effect of Gnidilatimonoein from Daphne Mucronata," Life Sciences, Vol. 74, No. 15, 2004, pp. 1869-1876. doi:10.1016/j.lfs.2003.08.039

[15] M. Hedayati, R. Yazdanparast and F. Azizi, "Daphne Mucronata Extracts Effects on down Regulation of TNF- $\alpha$ Receptors on Cultured Human Monocytes," Yakhte, Vol. 27, No. 7, 2005, pp. 152-157. (Persian)

[16] M. Hedayati, R. Yazdanparast, B. Jafari and F. Azizi, "Dendrostellera Lessertii Extract Effects on TNF- $\alpha$ Release and Its Receptors down Regulation on Cultured Human Monocytes," Pejouhesh, Vol. 29, No. 4, 2006, pp. 337-342. (Persian)

[17] B. Beatler, N. Krochin, I. W. Milsark, C. Luedke and A Cerami, "Control of Cachepsin (Tumor Necrosis Factor) Synthesis, Mechanism of Endotoxin Reistance," Science, Vol. 232, 1986, pp. 977-980. doi:10.1126/science.3754653

[18] A. H. Ding, F. Porteu, E. Sanchez and C. E. Nathan, "Shared Action of Endotoxin and Taxol on TNF-Receptor and TNF Release," Science, Vol. 284, 1990, pp. 370-373. doi:10.1126/science.1970196

[19] E. A. Carswell, L. J. Old, R. L. Kassel, S. Green, N. Fiore and B. Williamson, "An Endotoxine Induced Serum Factor that Cause Necrosis Tumors," Proceedings of $\mathrm{Na}$ tional Academy Sciences (USA), Vol. 72, 1975, pp. 3665-3668. doi:10.1073/pnas.72.9.3666

[20] J. N. Allen, S.A. Moore and N. W. Wewers, "Taxol Enhance but Not Induced IL-1 Beta and TNF- $\alpha$ Production," Clinical Research, Vol. 40, 1992, p. 744.

[21] M. O. Jianchu and C. H. Jiajan, "Advance on the Research of the Bioactivity of Daphne Plants," Natural
Product Research and Development, Vol. 15, No. 2, 2003, pp. 167-170.

[22] M. O. Jianchu, Z. H. Jun and W. Wenxue, "Action of Daphne Genkwa Alcohol Extract on the Digestive Enzymes of Abraxas Miranda and Pieris Rapae," Journal of Central South Forestry University, Vol. 21, No. 1, 2001, pp. 5-9.

[23] T. Vetrichelvan and M. Jegadeesan, "Effect of Alcohol Extract of Achyranthes Aspera Linn on Acute and Subacute Inflammation," Phytotherapy Research, Vol. 17, No. 1, 2003, pp. 77- 79. doi:10.1002/ptr.1070

[24] M. Mianabadi, E. Rivera and R. Yazdanparast, "A New Diterpene Ester from the Leaves of Daphne Mucronata," Journal of Tropical Medical Plants, Vol. 4, 2003, pp. 1-4.

[25] B. N. Meyer, N. R. Ferringne, J. E. Putnam, L. B. Jacobsen, D. E. Nicholas and J. L. Mclmaughlin, "Brine Shrimp: A Convenient General Bioassay for Active Plant Constituents," Plant Medica, Vol. 45, 1982, pp. 31-34. doi:10.1055/s-2007-971236

[26] D. J. Finney, "Probit Analysis," 3rd Edition, Cambridge University Press, Cambridge, 1971.

[27] S. Bunnett and S. N. Berit, "Variables in the Isolation and Culture of Human Monocytes that are of Particular Relevance to Studies of HIV," Journal of Leukocyte Biology, Vol. 56, 1994, pp. 236-240.

[28] M. Hedayati, R. Yazdanparast and F. Azizi, "Determination of Human Tumor Necrosis Factor Alpha by a Highly Sensitive Enzyme Immunoassay," Biochemical and Biophysical Research Communications, Vol. 289, 2001, pp. 295-298. doi:10.1006/bbrc.2001.5886

[29] M. Hedayati, R. Yazdanparast, H. Fasihi and F. Azizi, "Anti-tumor Activity of Daphne Mucronata Extract and Its Effects on TNF- $\alpha$-Receptors and TNF- $\alpha$ Release in Cultured Human Monocytes," Pharmaceutical Biology, Vol. 41, 2003, pp. 194-198. doi:10.1076/phbi.41.3.194.15093

\begin{abstract}
Abbreviation List
Enzyme Linked Immunosorbent Assay (ELISA), Ethylene Diamine Tetra Acetic acid (EDTA), Lipopolysaccharide (LPS), Phosphate Buffer Saline (PBS), Roswell Park Memorial Institute (RPMI), Tumor Necrosis Factor alpha (TNF-a)
\end{abstract}

